\title{
Methodological basis for the preservation and restoration of existing memorial complexes in the reconstruction of urban environment on the example of the city of Rostov-on-Don
}

\author{
Alisa Sokolova ${ }^{1, *}$, Svetlana Sheina ${ }^{1}$ \\ ${ }^{1}$ Don State Technical University, pl. Gagarina, 1, Rostov-on-Don, 344010, Russia
}

\begin{abstract}
The paper deals with the problem of the memorial complex as well as the importance of its preservation and reconstruction in the context of urban environment restoration. It forms the concept of the memorial complex and its role in the urban fabric. In considering the issue of the memorial complex, its effect on the urban layout is identified. Basing on the memorial function of complexes their key features are defined, and the reasons for their preservation and restoration are identified.
\end{abstract}

\section{Introduction}

Memorial complexes are cultural sites of any city, an integral part of its structure often playing an important role in urban development. But there are certain spatial location restrictions for memorial complexes regardless of their size. This is due to the fact that like any object of residential area the complex must be located in accordance with the spatial planning principles and zoning regulations. Landmark sights must not predominate over surrounding architecture or be lost in it, i.e. they must be compatible with a certain urban structure [1].

Changes of urban development situation (the emergence of new zones in the outlying districts, the expansion of old and creation of new street space and city blocks, creation of architectural ensembles which include open and closed space areas) are the hallmarks of civilizational transformations that accompany the development and determine the current state of social relations. The inevitable consequence of such changes is physical utilization of material objects of the passing era environment.

Architectural sites (construction objects) characterized by the original memorial function most often "fall victim" to architectural and city-planning solutions for changing functional and planning structure of the urban fabric, primarily due to the reduction of material value in the process of functioning. Only understanding of non-material (artistic) value contributes to the implementation of measures for restoration or reconstruction of a monument (a cultural and historic heritage site) regardless of its temporary utilitarian value $[2,3]$.

${ }^{*}$ Corresponding author: lisa.858@yandex.ru 


\section{Methods}

Preservation of the material value of architectural monuments (including heritage sites) can be quite possible by means of involving modern utilitarian functions, which can provide fund to maintain (extend) their service life in the current conditions (of preservation of their physical state under the effect of natural and climatic factors and functioning process).

Primarily, an important step in conservation of memorial complexes on the territory of any city is urban environment monitoring. The preservation of historic buildings on the monitoring basis requires consideration of:

a) the city-planning base characterized by historic development and space planning pattern formation of the historic part of the city;

b) sanitary requirements to the geological features and environmental profile of the historic district area;

c) technical specifications, considered for preservation of memorial complexes.

In accordance with the purpose and objectives of this research, a set of all monitoring information is divided into urban, environmental and technical components. Historic development area (Figure 1) and its setting, ecological environment of the historic development area, technical condition and pragmatic use of the memorials are the objects for presenting monitoring data [4].

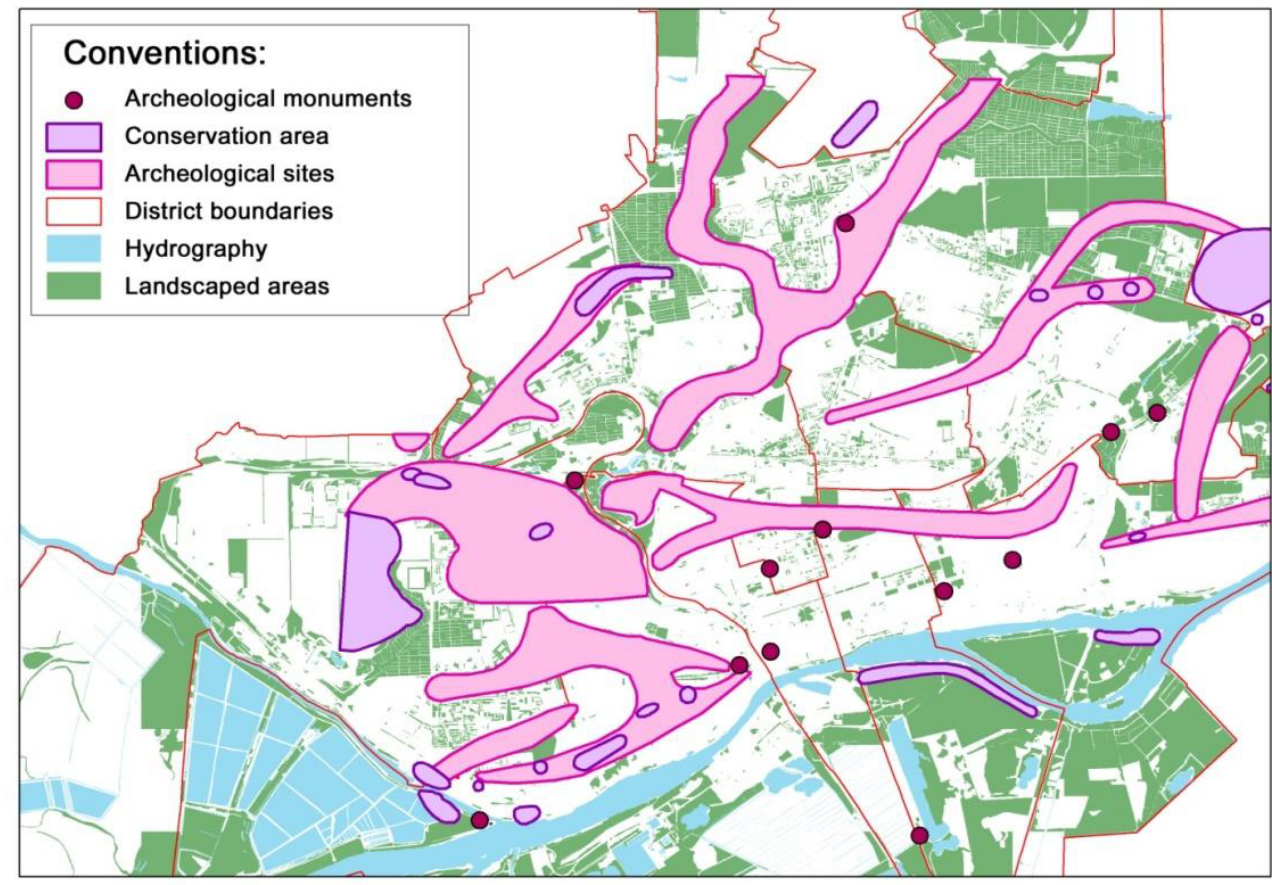

Fig. 1. Map of memorial complexes location in historical district of Rostov-on-Don.

The obtained data must be influencing parameters for the effective urban sustainable decision model for preservation and restoration of memorial complexes and their adjacent areas.

With regard to the methods of maintaining the physical state (preserving the material value)of the memorial, we should point out the organization of protected zones, areas (open spaces) adjacent or within the structure of the memorial complex, which are designed to provide optimum conditions for their preservation and/or visual perception [5]. In certain 
cases it is quite acceptable to implement changes in the adjacent development, which can enhance the esthetic impression of the restored or existing memorial.

\section{Results}

To conduct this research anArcGIS geo-informational database of Rostov-on-Don memorial complexes was created (Figure 2).The developed GIS-project "Memorial Complexes of Rostov-on-Don" contains thematic layers of the e-map with the database of major memorials, data on geological and ecological condition of the memorial complex zone. The e-map includes twelve (12) memorial complexes (Table 1) containing the following information:

- memorial complex name, photograph;

- location, address;

- architect, sculptor;

- functional profile;

- urban significance features;

- usage pattern profile;

- the origin of the monument;

- material and non-material features of the memorial structures.

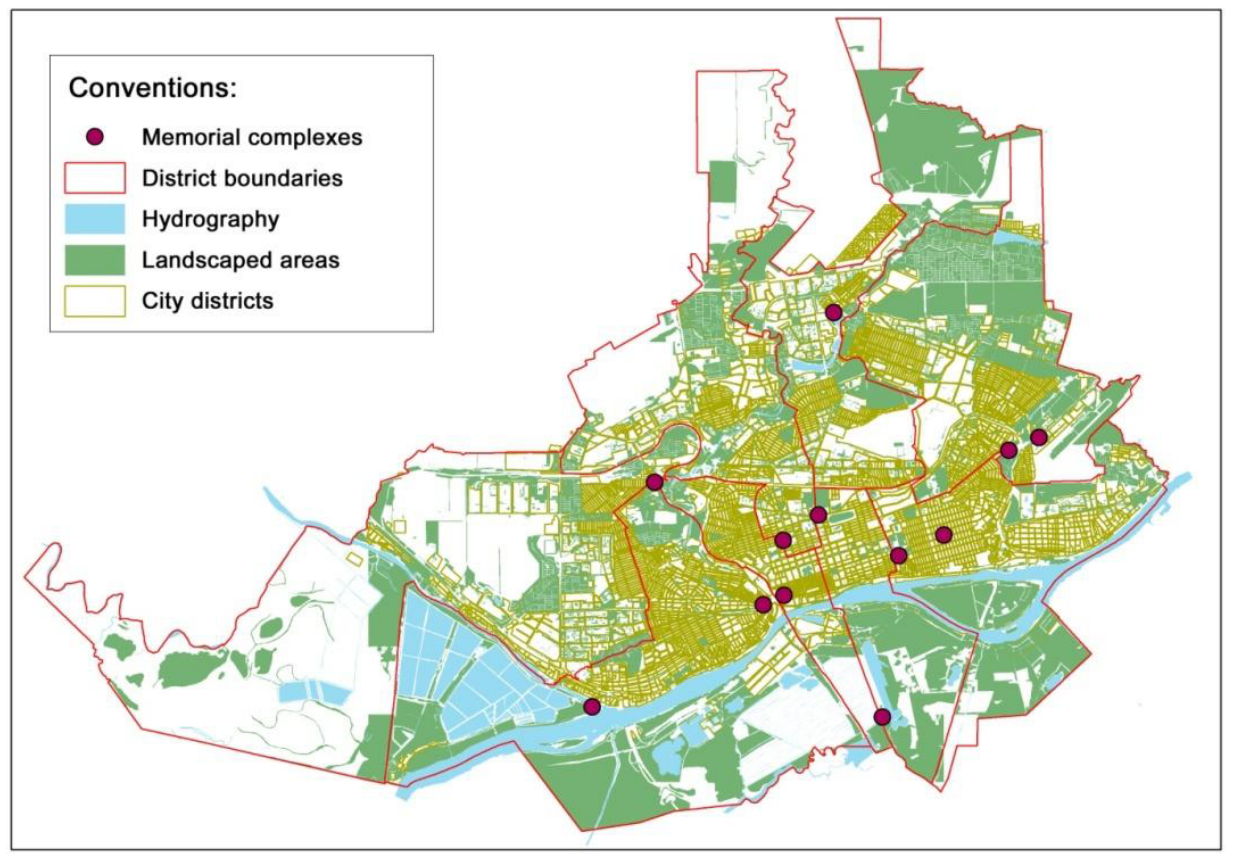

Fig. 2.Map of memorials location on the territory of Rostov-on-Don.

The developed project allows:

- conducting a comprehensive environmental evaluation of the city of Rostov-on-don including geological and ecological risk assessment (Figure 3);

- evaluating memorial complexes location conditions;

- classifying the memorial complexes by the their functional profile, urban significance features, usage pattern profile, material and non-material features and the origin of the memorials; 
- identifying priority areas for creating new and/or reconstructing the existing memorial complexes;

- drafting a number of proposals based on the comprehensive evaluation results to preserve and reconstruct Rostov-on-Don memorial complexes.

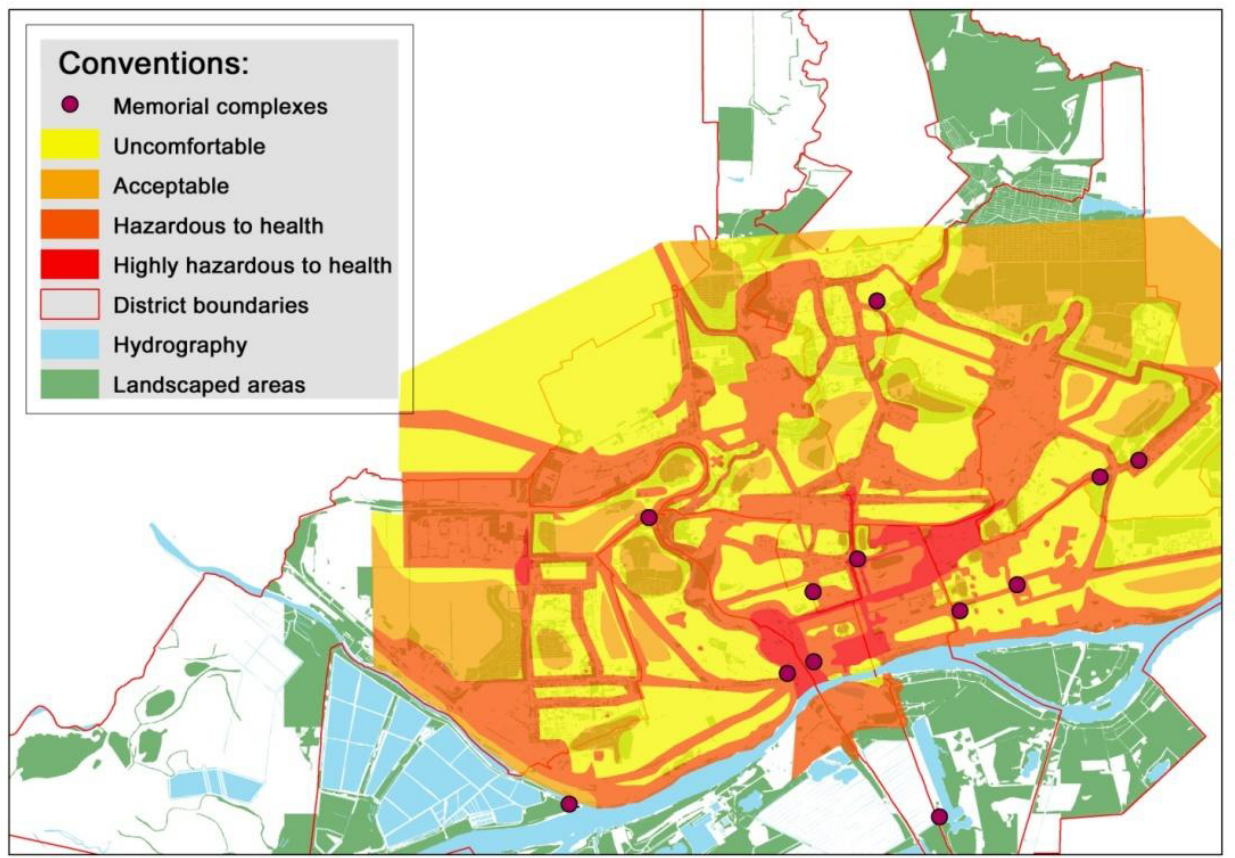

Fig. 3. Map of memorial complexes location in ecologically risky zones of Rostov-on-Don.

Table1.Rostov-on-Don memorial complexes.

\begin{tabular}{|c|c|c|c|c|c|}
\hline & $\begin{array}{c}\text { Memorial complex } \\
\text { name }\end{array}$ & Photograph & 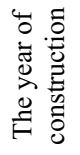 & $\begin{array}{l}\text { Geological } \\
\text { risk area }\end{array}$ & $\begin{array}{l}\text { Ecological } \\
\text { risk area }\end{array}$ \\
\hline 1 & $\begin{array}{l}\text { Memorial complex "To } \\
\text { the memory of the } \\
\text { victims of fascism in } \\
\text { ZmiyovskayaBalka } \\
\text { (cavin)" }\end{array}$ & & 1975 & $\begin{array}{l}\text { Low } \\
\text { hazardous- for } \\
\text { loessial } \\
\text { collapsiblesoils } \\
\text { of type I }\end{array}$ & $\begin{array}{l}\text { Low } \\
\text { hazardous }\end{array}$ \\
\hline 2 & $\begin{array}{l}\text { Memorial complex } \\
\text { «KumzhenskayaRoscha } \\
\text { (grove)» }\end{array}$ & & 1983 & $\begin{array}{l}\text { Low hazardous } \\
\text { - for loessial } \\
\text { collapsible } \\
\text { soils of type II }\end{array}$ & Hazardous \\
\hline 3 & $\begin{array}{l}\text { Memorial complex to } \\
\text { the } 1902 \text { strike. High } \\
\text { relief, } 1967 \text { - sculptural } \\
\text { composition } \\
\text { "Continuity of } \\
\text { generations" }\end{array}$ & & $\begin{array}{l}1967 \\
1975\end{array}$ & $\begin{array}{l}\text { Low hazardous } \\
\text { - for loessial } \\
\text { collapsible } \\
\text { soils of type I }\end{array}$ & $\begin{array}{l}\text { Highly } \\
\text { hazardous }\end{array}$ \\
\hline
\end{tabular}




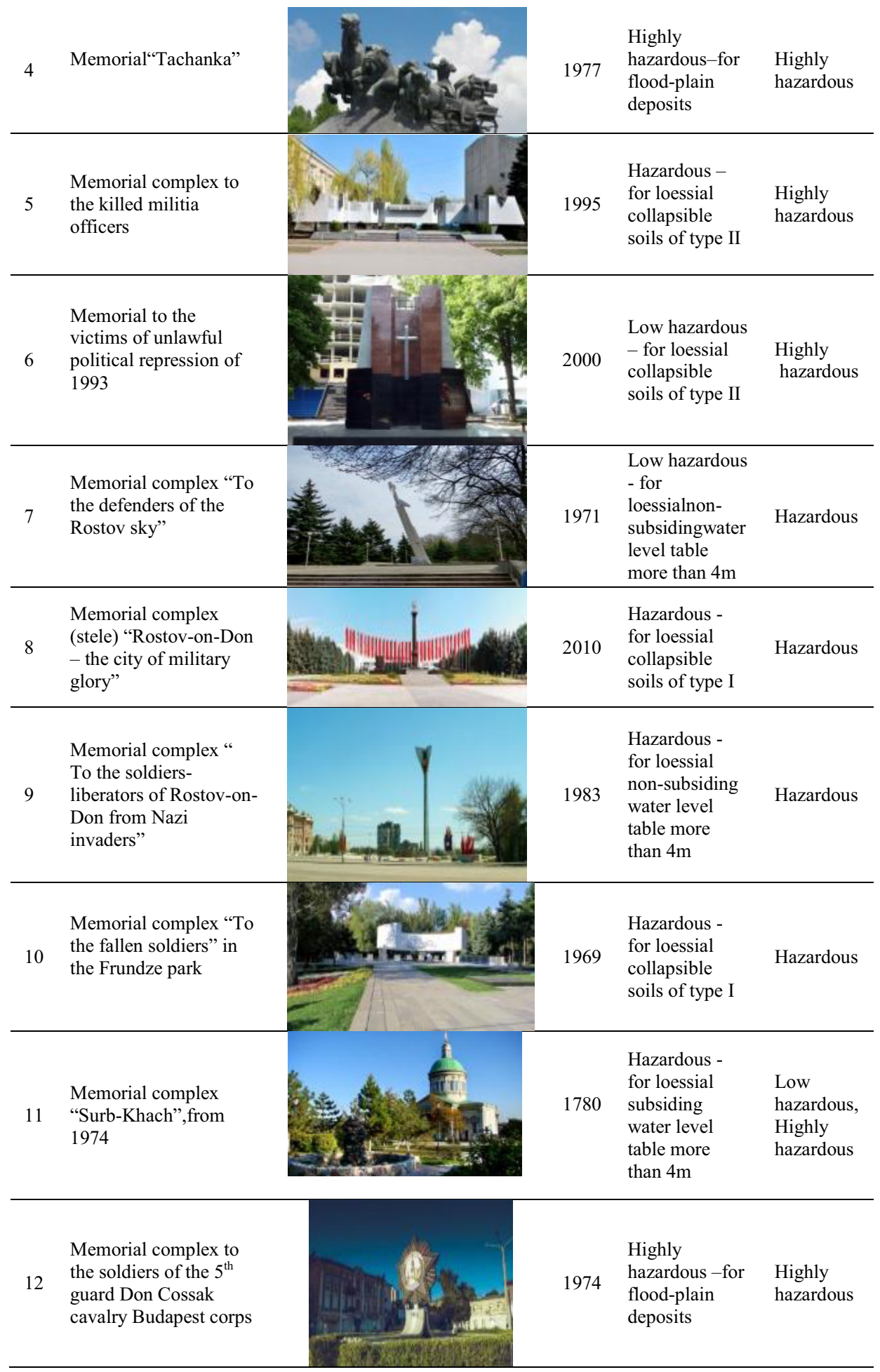




\section{Discussion}

The spatial analysis allowed determining that memorial complexes are located in highly hazardous, hazardous and low hazardous geological risk areas. To preserve and restore the memorial complexes it is necessary to develop measures for reduction or elimination of the environmental effect. The use of modern environment monitoring systems will allow developing measures and methods of preserving the existing memorial complexes and creating the new ones.

\section{Conclusions}

In conclusion I want to note that It is necessary to actively use the open space area facilities around the existing memorial for creating a new memorial object when restoring the urban environment. The most suitable urban planning opportunities for such solutions are available in the outlying districts of the urban fabric, areas around linear traffic structures (highways and railways),riparian lands of rivers, lakes and water reservoirs.

\section{References}

1. The federal law 73-FZ. 25.02.2002

2. V. Kokh, BMM AO Pbl., 528 (2005)

3. S.G.Zmeul, B.A.Makhanko, Arkhitektura S.Pb, 241 (2004)

4. S.G.Sheina, L.L.Babenko, P.A.Shumeev, Inzhenernyivestnik Dona,4 (2012)

5. S.G.Sheina, L.V.Giria, Inzhenernyivestnik Dona, 4 (2011) 